\title{
Deforestation and degradation in Papua New Guinea: a response to Filer and colleagues, 2009
}

\begin{abstract}
Papua New Guinea's (PNG) forests are a vital natural resource for the human population that they sustain, the wide biological diversity they contain, the ecological services they provide and their global role in maintaining climatic processes (Hunt, 2006; Bryan et al., in press). The population of PNG is expanding by approximately $2-3 \%$ annually, requiring forest clearance for subsistence cultivation, and over recent decades the log export industry has expanded greatly. Though these and other drivers of forest change are well known, there has been considerable debate regarding the extent and rate at which forests are being degraded or converted to other forms of land use. This debate has been fuelled by an absence of recent accurate data, and coloured by the politics associated with industrial rainforest exploitation and more recently, carbon-related REDD projects ${ }^{1}$. To address this deficiency we undertook a 6-year research project that involved mapping the entire PNG forest estate at high resolution, and compared this with maps from the early 1970s. Our results provide detailed, accurate measurement of the area and condition of forest in PNG, how much forest has been cleared or degraded over the past three decades, and what caused these changes. Our research was initially published as a detailed report (Shearman et al., 2008) that has also been published, in abbreviated form, in the peerreviewed journal Biotropica (Shearman et al., 2009). Our most controversial finding was that overall rates of forest clearance and degradation were much higher than those estimated in the early 1990s (Hammermaster and Saunders, 1995; McAlpine and Quigley, 1998; McAlpine and Freyne, 2001). This is partly because the rates are accelerating but it is mostly due to technical differences in measuring forest cover and forest cover change.
\end{abstract}

Our research has been widely cited and accepted, however Filer et al. (2009) question some of the findings in Shearman et al. (2008), and we take this opportunity to address these issues. Many of the comments in Filer et al. (2009) suggest that the authors have placed undue reliance on older studies of PNG forests (notably Hammermaster and Saunders, 1995: Forest Inventory Mapping System, FIMS) and are unfamiliar with the strengths and limitations of the various techniques that have been used for monitoring vegetation cover and change. It is important to appreciate that FIMS was intended to assess the stocks of various forest types at a broad scale, including areas that had been commercially logged; it

\footnotetext{
${ }^{1}$ REDD: Reduced Emissions from Deforestation and Degradation.
}

was not designed specifically to measure or monitor vegetation change at a fine spatial scale. We firstly outline and contrast the methods used in FIMS and Shearman et al. (2008; 2009) before addressing specific comments by Filer et al. (2009).

There have been three distinct phases in the recent mapping of forest vegetation across Papua New Guinea (PNG): (i) aerial photography from the early 1970s that generated $\pm 40 \mathrm{~m}$ spatial resolution topographic and vegetation mapping (Coulthard-Clark, 2000), (ii) early 1990s vegetation maps based upon interpretation of the same 1970s aerial photography and moderate resolution printed satellite images (Hammermaster and Saunders, 1995; hereafter called FIMS the "Forest Inventory Mapping System"), and (iii) early 2000s vegetation maps based upon digital processing of high resolution satellite data (Shearman et al., 2008; 2009).

In common with the FIMS study, we used as our "baseline", vegetation maps drawn from the same 1970s aerial photographs. However, there was a critical difference in the procedure for defining boundaries on the FIMS maps and our maps. FIMS boundaries were approximate: according to the authors of the study, the FIMS vegetation boundary vectors possessed a positional accuracy of $\pm 250 \mathrm{~m}$, but were in fact commonly $\approx 1 \mathrm{~km}$. They were generally drawn inside intact forest margins (so they slightly underestimate forest area) using smooth handdrawn curves that ignored the convolutions of forest margins. Where the vegetation was patchy or the boundaries were particularly convoluted, instead of mapping the boundary, a polygon was drawn to enclose the area, that was then labelled as a mixture of vegetation types. One consequence was that FIMS did not and could not identify small areas that had changed, an issue discussed further below. The FIMS process allocated less than 10 person-years to the forest-mapping task.

In contrast we chose to use the vegetation maps produced by the Royal Australian Survey Corps that also used the 1970s aerial photography. The Royal Australian Survey Corps committed 300 person-years to the production of these maps. The maps are spatially accurate to $\pm 40 \mathrm{~m}$, and reliable when we tested them against the aerial photographs for each of the 300 + resulting mapsheets (Shearman et al., 2009). The Army maps only classified land cover into nine classes, but it did so with a high degree of precision and accuracy, particularly at the crucial forest/non-forest boundary. Despite evident advantages of the Army maps, Filer et al. (2009) perversely suggest that the FIMS maps are preferable. Indeed it is understood that the reason why FIMS did not use the Army boundaries was 
because FIMS aimed to classify land cover into some 63 primary classes and several hundred "complexes". It did this so that these classes could be combined with timber volume inventory data. The principle aim of FIMS was to develop data to underpin the forestry industry, not to develop baselines for change detection.

Though both the FIMS "1996" and our "2002" vegetation maps are both based on satellite data, they differ in several ways that are important for measuring vegetation change. Instead of using orthorectified digital imagery, FIMS acquired unorthorectified prints from the early 1990s (but specified as "1996"), produced at an approximate scale of at least 1:250 000. The use of prints meant that the satellite imagery could not be precisely superimposed on their 1972 maps in a GIS system. The FIMS 1970s vector coverage and the image prints were also orthocorrected differently, creating uncontrolled positional deviations. Technical issues associated with the transferral of data from the prints to the GIS platform resulted in some errors in the location of vegetation features by up to several kilometers. These various issues had several important ramifications for detecting change. Only large differences between the 1970s vectors and 1990s prints could be detected - indeed this process did not create a new 1990s surface, it just selected polygons from the FIMS 1970s baseline polygon coverage that were apparently most obviously deforested from visual examination of the 1990s hard copy prints. Consequently, the FIMS change assessment was skewed towards the identification of large areas that had possibly been cleared, and away from assessing small-scale change and forest-edge clearance that one would expect would be associated with the expansion of the subsistence agricultural zones, or other drivers of forest-change. In total only 488 "change" polygons were created. The minimum size of these polygons was approximately $1 \mathrm{~km}^{2}$ and there were very few (17) of this size. The average size of "change" polygon in FIMS is approximately 3000 ha or $30 \mathrm{~km}^{2}$ - a discrete area far larger than is likely to occur in $\approx 20$ years from increasing the size or number of food gardens, and much larger than the width of a logging road. Indeed we wonder why Filer et al. (2009) did not ask why change had apparently occurred in only 488 areas of the country. Surely if it was happening across these large zones, it was likely to be occurring in many smaller zones as well?

In contrast, to generate a 2002 wall-to-wall forest map of PNG, we used high resolution 7-band digital satellite data (and some 4 band SPOT4 \& 5), a new SRTM $90 \mathrm{~m}$ resolution digital elevation model (and Ground Control Points) to orthorectify images, and digital pattern recognition techniques to assist in vegetation classification. Together these enabled us to map boundaries more precisely and accurately as well as generating an actual forest cover map (Shearman et al., 2008; 2009). Our classifications were field-verified using a statistically robust aerial survey program. As both of our 1972 and 2002 maps were orthorectified to grid co-ordinates we could precisely superimpose them and measure changes in boundary location with confidence (about $\pm 50 \mathrm{~m} \mathrm{sd}$ ) of a minimum area of change of 1 ha.

Though we initially planned to use FIMS "1975" and "1996" vegetation maps as baselines for comparison with our
"2002" map, the technical limitations of unrectified data and incomplete and approximate boundary mapping in FIMS persuaded us that this could not be justified (see discussion in Shearman et al., 2008; 2009). There was nothing superficial or devious about this: we went to great lengths to test both the FIMS maps and the Army maps before accepting the latter as the better baseline: a decision that added more than two years' work to our project.

Overall, it is highly likely that the scale and methods used in FIMS generally resulted in an overestimation of the size of large discrete cleared areas and areas of non-forest (and underestimated forest areas), and in most places generated an underestimation of small-scale change that was occurring across the landscape through a gradual process of nibbling at forest margins or the creation of new food gardens within forested areas. The FIMS vegetation complexes provided no boundaries for comparison. Further, the positional errors associated with the generalization of complex vegetation boundaries and their transferral to a GIS platform, were such that the FIMS polygons cannot be used as a baseline for new assessments of vegetation change.

Suggestions by Filer and colleagues that the 1990s FIMS, MASP and PNGRIS maps could be used to assess forest change indicate that they do not understand the limitations of those studies and did not read our discussion of these issues in Shearman et al. (2008). Indeed, MASP (Mapping Agricultural Systems in PNG) (Bourke et al., 1998) did not attempt to map forests at all - it defined agricultural zones at a 1:500 000 scale. While PNGRIS was technically advanced for its time, it could not be used for accurate change analyses of forestry assessments. This was because of two reasons. PNGRIS incorporated forest descriptions at a 1:1000 000 scale (derived from the CSIRO Land Research series and 1970s aerial photography) as a "field" within a 1:500 000 representation of PNG landforms (Bellamy and McAlpine, 1995). The basic unit of mapping, the landform, does not commonly concur with forest boundaries, and in any case, the scale of the mapping was too coarse to accurately reflect forest boundaries. Indeed, an upgraded version of PNGRIS was created at a much finer scale in 2008 in order to overcome these spatial limitations (Bryan and Shearman, 2008). Discussion and examples showing the limitations of FIMS and PNGRIS have been published in Shearman et al. (2008), Bryan and Shearman (2008) and Shearman et al. (2009), yet have been ignored by Filer et al. (2009). FIMS, MASP and PNGRIS have all proved valuable for the goals for which they were intended but they have limitations as baselines for precisely measuring vegetation change.

In the mid-1990s, FIMS came to have a central role as a source of summary information on PNG forests, so our decision to discard it from our analysis of forest change surprised and evidently angered some of those who had come to heavily rely upon it in their publications. The FIMS study estimated the average annual rate of forest change (1975-1996) as $0.5 \%$, which is lower than in many other tropical countries and suggested that human impacts were relatively minor. Rates of forest change (early-1970s to early-1990s) estimated from FIMS were also treated as constants by some users of that survey (FAO, 2005a; 2005b), even though a cursory consideration 
of the drivers of change such as subsistence-related activity, population size and timber exports show well-documented increases over recent decades. Our estimate that by 2002 the overall rate of forest change was $\approx 1.4 \%$ does necessitate the re-evaluation of the impacts of logging, fires, subsistence activity and other drivers of forest change in PNG.

In summary, neither FIMS nor MASP nor PNGRIS provide sufficiently accurate forest boundaries at an appropriate scale against which forest change and condition can adequately be measured. We do not therefore provide further discussion of each individual statement or argument made by Filer et al. (2009) where FIMS, MASP or PNGRIS derived data have been used as supporting evidence. However, there are several other miss-statements of fact, or misrepresentations made by Filer and colleagues (2009) that are now addressed.

Filer and colleagues (Section 2.1, p. 3) claim there was "semantic confusion" over our forest definitions. However we provided precise logical definitions of forest types, deforestation and degradation at the outset, and applied these rigorously in Shearman et al. (2008; 2009). Our use of terms follows those widely accepted in the field (Olander et al., 2008; Paijmans, 1976).

Filer et al. (2009) suggest that much of what we recorded as net forest loss via subsistence-related activities, and also net loss and degradation due to logging, could be regenerated in future, and therefore imply we ought not to have measured it. This is a strange argument given one of the main aims of our study was to measure actual forest change over the past 30 years, not potential future change. Filer et al. (Section 2.2, p. 5) also claim we have assumed that degraded or cleared forest cannot regenerate, an assumption we certainly never made. Clearly, some regeneration of degraded forest is likely, and we did incorporate regeneration over the study period: our summary statistics represent net change as we measured both forest loss and gain. We found substantial net deforestation and degradation of forest due to logging, with $23 \%$ of the logged forest area being deforested within the study period - the remaining $77 \%$ being degraded. Clearly we are unable to predict exactly how much regeneration will occur in future given the acceleration of human impacts and influences of climate change. Contrary to findings from FIMS, we found substantial net subsistence-related clearing, suggesting that increasing rural populations are causing deforestation and not merely increased agricultural intensification. This cannot be dismissed as part of the normal cultivation cycle as Filer et al. (Section 2.2, p. 5) suggest, because we measured both forest gain and loss over 30 years, and found a substantial net loss. The reason that FIMS did not detect much net subsistence-related clearing appears to be due to the lower resolution and precision of that study (discussed above).

Filer et al. (Section 3.1, p. 7) claim that there is no link between rainforest logging and fire, despite evidence to the contrary both in PNG and other countries (Cochrane and Laurance, 2008, Nepstad, et al., 1999). We recorded areas deforested by fire within logged lowland forest, which spread into some adjacent unlogged forest, and also fires in unlogged sub-alpine forest that probably spread from adjacent grassland. We included photographs and images of a number of these burned areas in Shearman et al. (2008), and additional field verification in Shearman et al. (2009). Filer et al. (Section 3.1, p. 7) imply that we have claimed that deforestation is occurring because landless migrants have invaded logged forests. In fact we stated that this has not occurred to an appreciable extent.

Filer et al. (Section 2.2, p. 5) state that the impact of industrial logging activity mirrors that of subsistence cultivation, yet they do not provide any evidence to support this assertion. They state this despite much evidence showing that the impacts of industrial logging are substantially different to that of subsistence-related clearance, in location, intensity and ecological implications (Asner et al., 2006; 2009; Putz et al., 2000; Sist et al., 2003; Sist and Brown, 2004).

Filer et al. (Section 4.3, p. 10) state there is no evidence that we "consciously inflated" our estimated rates of deforestation, disingenuously implying that the estimates are inflated. This is not correct. Filer et al., (2009) may believe this in part due to their reliance on FIMS data, but also because they have attempted to estimate annual logged area from approximate harvest intensities, with only an indirect and approximate link to area change (Section 3.2, p. 7). In contrast, we estimated the annual logged area between 1972 and 2002, from the direct physical measurement of logged area over this period. Filer et al., failed to find any evidence that our results were inflated, precisely because they were not.

Filer et al. (Section 3, p. 6) query our measured areas of logged forest, deforestation due to fire, the area cleared via subsistence-related activities and plantations (oil palm, cocoa, coconut etc.) but offer no recent data or evidence to back their assertions. It is hard to address such comments beyond reiterating the limitations of past estimates such as those in FIMS and the accelerating rate of change in PNG.

We welcome scientific debate and rigorous review of our research but are disappointed that some critical comments by Filer et al. (2009) appear to stem from a lack of appreciation of current techniques of measuring nationwide vegetation change, uncritical acceptance of past studies and the belief that long-held opinions have the weight of scientific measurement.

\section{Philip L. Shearman ${ }^{1,2}$ Jane Bryan $^{1,2}$, Julian Ash ${ }^{3}$, Brendan Mackey ${ }^{4}$, Barbara Lokes ${ }^{1}$}

\footnotetext{
${ }^{1}$ UPNG Remote Sensing Centre, P.O. Box 320, Biology Department, University of Papua New Guinea, Waigani, Port Moresby, Papua New Guinea

${ }^{2}$ School of Geography and Environmental Studies, University of Tasmania, Private Bag 78, Hobart, Tasmania, 7001, Australia

${ }^{3}$ School of Botany and Zoology, The Australian National University, Linnaeus Way, ANU, Canberra, 0200, Australia

${ }^{4}$ Fenner School of Environment and Society, The Australian National University, Linnaeus Way, ANU, Canberra, Australia
} 


\section{REFERENCES}

Asner G.P., Broadbent E.N., Oliveira P.J.C., Keller M., Knapp D.E., and Silva J.N.M., 2006. Condition and fate of logged forests in the Brazilian Amazon. Proc. Natl. Acad. Sci. USA 34: 12947-12950.

Asner G.P., Keller M., Lentini M., Merry F., and Souza C Jr., 2009. Selective logging and its relation to deforestation. In: M. Keller, J. Gash, and P. Silva Dias (Eds.), Amazonia and global change, American Geophysical Union.

Bellamy J.A. and McAlpine J.R., 1995. Papua New Guinea inventory of natural resources, population distribution and land use, 2nd ed. PNGRIS Publication No. 6, Commonwealth Scientific and Industrial Research Organization, Canberra.

Bourke R.M., Allen B.J., Hobsbawn P., and Conway J., 1998. Agricultural Systems of Papua New Guinea. Working Papers, The Australian National University.

Bryan J.E. and Shearman P.L., 2008. Papua New Guinea resource information handbook, 3rd ed. University of Papua New Guinea, Port Moresby.

Bryan J.E., Shearman P.L., Ash J., and Kirkpatrick J.B., 2010. Estimating rainforest biomass stocks and carbon loss from deforestation and degradation in Papua New Guinea 1972-2002: best estimates, uncertainties and research needs. J. Environ. Manage. (in press).

Cochrane M. and Laurance W., 2008. Synergisms among fire, land use, and climate change in the Amazon. Ambio 37: 522-527.

Coulthard-Clark C.D., 2000. Australia's military map-makers: The Royal Australian Survey Corps 1915-1996. Oxford University Press, Melbourne, Australia.

FAO, 2005a. Global Forest Review Assessment, 2005. FAO, Rome.

FAO, 2005b. Global Forest Review Assessment 2005. Papua New Guinea Country Report, FAO, Rome.

Filer C., Keenan R.J., Allen B.J., and McAlpine J.R., 2009. Deforestation and forest degradation in Papua New Guinea. Ann. For. Sci. 66: 813. (Published Online: 25 November 2009.)

Hammermaster E.T. and Saunders J.C., 1995. Forest resources and vegetation mapping of Papua New Guinea. CSIRO, Canberra, Australia.
McAlpine J.R. and Freyne D.F., 2001. Land use change and intensification in Papua New Guinea 1975-1996. Asia Pacific Viewpoint 42: 209-218.

McAlpine J. and Quigley J., 1998. Forest resources of Papua New Guinea. Summary statistics from the Forest Inventory Mapping (FIM) System, Papua New Guinea: Coffey MPW Ltd for the Australian Agency for International Development and the Papua New Guinea National Forest Service.

Nepstad D.C., Verissimo A., Alencar A., Nobre C., Lima E., Lefebvre P., Schlesinger P., Potter C., Moutinho P., Mendoza E., Cochrane M., and Brooks V., 1999. Large-scale impoverishment of Amazonian forests by logging and fire. Nature 398: 505-508.

Olander L.P., Gibbs H.K., Steininger M., Swenson J., and Murray B., 2008. Reference scenarios for deforestation and forest degradation in support of REDD: a review of data and methods. Environ. Res. Lett. 3: 025011.

Paijmans K. (Ed.), 1976. New Guinea Vegetation. CSIRO and ANU, Australian National University Press, Canberra.

Putz F.E., Dykstra D.P., and Heinrich R., 2000. Why poor logging practices persist in the tropics. Conserv. Biol. 14: 951-956.

Shearman P.L., Bryan J.E., Ash J., Hunnam P., Mackey B., and Lokes B., 2008. The State of the Forests of Papua New Guinea. Mapping the extent and condition of forest cover and measuring the drivers of forest change in the period 1972-2002. University of Papua New Guinea, 2008.

Shearman P.L., Ash J., Mackey B., Bryan J.E., and Lokes B., 2009. Forest conversion and degradation in Papua New Guinea 1972-2002. Biotropica 41: 379-390.

Sist P., Fimbel R., Sheil D., Nasi R., and Chevallier M., 2003. Towards sustainable management of mixed dipterocarp forest of South-east Asia: moving beyond minimum diameter cutting limits. Environ. Conserv. 30: $364-374$

Sist P. and Brown N., 2004. Silvicultural intensification for tropical forest conservation: a response to Fredericksen and Putz. Biodiv. Conserv. 13: 2381-2385. 